\title{
Estudo anatômico das veias soleares em humanos
}

\author{
Anatomic study of the soleus veins in human beings
}

Carlos Miguel Gomes Sequeira*

\begin{abstract}
Resumo
Introdução: A etiopatogenia das doenças tromboembólicas e venosas nos membros inferiores está mais freqüentemente relacionada às veias do músculo sóleo, que é o mais usado para compor os retalhos miocutâneos pediculados.
\end{abstract}

Objetivos: Estudar o número, localização, plano de terminação e terminação das veias soleares.

Método: Em 100 pernas de 50 cadáveres, excluídos aqueles com alterações congênitas ou adquiridas dos membros inferiores, foram realizadas dissecções anatômicas minuciosas e estratigráficas, a fresco, na região crural posterior. Após o rebatimento da pele, foram realizados os seguintes procedimentos: individualização das veias superficiais e perfurantes, rebatimento da tela subcutânea e da fáscia, individualização e rebatimento dos músculos gastrocnêmio e plantar, desinserção tibial do músculo sóleo, individualização das veias soleares e estudo morfométrico. A região foi dividida

\footnotetext{
* Professor adjunto, Departamento de Cirurgia, Universidade Federal do Rio de Janeiro (UFRJ), Rio de Janeiro, RJ. Doutor em Cirurgia Vascular, Universidade Federal de São Paulo - Escola Paulista de Medicina (UNIFESP-EPM), São Paulo, SP. Membro titular, Colégio Brasileiro de Cirurgiões (CBC). Membro efetivo, SBACV.

Tese apresentada à UNIFESP-EPM para a obtenção do título de Doutor em Ciências, Curso de Pós-Graduação em Cirurgia Vascular, Cardíaca, Torácica e Anestesiologia, Área de Concentração Cirurgia Vascular. Trabalho realizado na Faculdade de Medicina da UFRJ e na UNIFESP-EPM.

Orientador: Prof. Dr. Fausto Miranda Júnior

Apresentação: 24/11/2005

Banca examinadora: Prof. Dr. Fausto Miranda Júnior, Prof. Dr. José Carlos Prates, Prof. Dr. Luis Francisco Poli de Figueiredo, Prof. Dr. Carlos Eli Piccinato, Prof. Dr. Walter Castelli Júnior.

Correspondência: cmgsequeira@ig.com.br

Resumo submetido em 01.09.06, aceito em 21.02.07.

J Vasc Bras 2007;6(1):101-101.

Copyright $@ 2007$ by Sociedade Brasileira de Angiologia e de Cirurgia Vascular.
}

em seis setores: súpero-medial, súpero-lateral, médiomedial, médio-lateral, ínfero-medial e ínfero-lateral. Os parâmetros idade, sexo, cor, biótipo, lateralidade, altura perna-pé, comprimento e largura do músculo sóleo foram correlacionados com o número, localização, plano de terminação e terminação das veias soleares. No estudo estatístico, foram utilizados os testes nãoparamétricos de Mann-Whitney, Wilcoxon, KruskalWallis, Spearman e Friedman.

Resultados: Foram encontradas 4.679 veias soleares. $\mathrm{O}$ setor com maior número de veias soleares foi o súpero-lateral, com 1.529 veias $(32,7 \%)$, seguido do médio-medial com 1.256 veias $(26,8 \%)$ e do médiolateral com 975 veias $(20,8 \%)$. O plano mais freqüente de terminação das veias soleares foi o profundo $(62,4 \%)$. As terminações ocorreram em veias comunicantes (1. 207 veias - 25,8\%), veias tibiais posteriores (964 veias $20,6 \%$ ), veias fibulares (709 veias - $15,2 \%$ ) e em mais 32 tipos (1.799 veias - 38,4\%). A média da altura perna-pé foi de $45,3 \mathrm{~cm}$, e o comprimento e largura do músculo sóleo, de 39,4 e 8,3 cm, respectivamente.

Conclusões: A drenagem venosa do músculo sóleo é realizada por um grande número de veias soleares, freqüentemente localizadas nos setores súpero-lateral, médio-medial e médio-lateral, em plano profundo, terminando comumente em veias tibiais posteriores, fibulares e em veias comunicantes. Os mediolíneos têm mais veias soleares, e os longilíneos, maior altura perna-pé e músculos sóleos mais longos.

Palavras-chave: Músculo sóleo, veias, homem, anatomia. 